\title{
O Escudo DE AQUILES
}

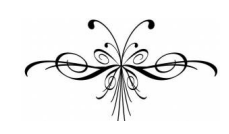

HOMERO

Juvino Alves MaIA JÚNIOR

\begin{abstract}
Resumo: Um dos trechos mais estudados e de pouca unanimidade da Ilíada (Canto XVIII, vv. 478-608), que trata do escudo de Aquiles, é aqui traduzido levando o tradutor a optar por uma versão que considera a mais coerente de acordo com sua interpretação. A estrutura do texto fonte e suas características linguísticas são uma condicionante para a tradução que ora se apresenta.
\end{abstract}

Palavras-chave: Ilíada. Escudo de Aquiles. Interpretação e tradução.

\begin{abstract}
One of the most studied excerpts in the Iliad (Book XVIII, lines 478-608), which tells of the Shield of Achilles, is not unanimously interpreted. We herein offer a translation of this excerpt according to our perception of which interpretation is more consistent. The structure of the source text as well as its linguistic features constitute the interpretive basis of this translation.
\end{abstract}

Keywords: Iliad. Shield of Achilles. Interpretation and translation.

$\mathrm{O}$ trecho da Ilíada do Canto XVIII que compreende os versos 478 a 608 está entre aqueles que mais foram estudados isoladamente, 0 que se verifica ao buscar referências bibliográficas que se avolumaram desde o século XX, incluindo estudos diretos e indiretos desde a Antiguidade e Idade Média. A crítica literária não está de acordo com diversas versões de interpretações e traduções que têm defensores com argumentos que se equivalem. O exemplo mais evidente é a construção do próprio escudo, com suas cinco camadas, que se explicam como as tradicionais camadas dos escudos dos heróis, de couro cada uma, ou como regiões em que Hefesto aplica sua arte, com mente vidente, atributo de um deus, concedido somente a ele. Outra polêmica é quanto à forma do escudo. Já que a crítica não chega a um termo de concordância, é preciso que o tradutor adote uma ou outra versão, para que a tradução seja coerente, dentro do que se interpretou. Então o escudo é redondo, maciço, todo de metal fundido, a saber cobre, estanho, ouro e prata, sem considerar as proporções que só Hefesto saberá. Portanto as camadas serão as partes representadas artisticamente, em número de cinco, encerrando-se a obra com o Rio-oceano que define o que está contido nele. Cada parte chamarei de ciclo, uma vez considerada a versão da circularidade concêntrica, dividida pelo artista por tema e por certa escolha de verbos e números que caracterizam cada ciclo. 
Nos primeiros cinco versos, está definida a confecção do escudo, com sua tríplice orla brilhante e sua tira prateada, com as cinco regiões ou ciclos definidos, em que serão inscritas figuras com arte que fazem supor movimento, obra de um deus.

Em 483 inicia-se o primeiro ciclo, como elemento fundador da criação relativa ao cosmos e aos elementos naturais constituintes da vida. Nesse ciclo prevalece a ideia do uno, centro de toda criação, que é modelo divino para a polis, criação humana, circular e elevada no centro, com linhas retas em ângulo reto para a habitação dos

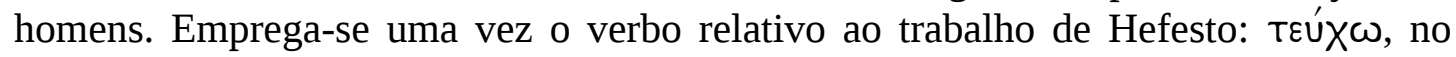
aoristo.

Em 490 inicia-se o segundo ciclo, com a criação de duas cidades, uma em paz, outra em guerra. Na primeira, há duas cenas: bodas de casamento e fórum de julgamento. Todos os elementos convergem para a duplicidade, como elementos de morfologia e sintaxe e de sentido. O verbo empregado no início da descrição é To। $\varepsilon \omega$, no aoristo, e para cada descrição das cenas nas duas cidades empregam-se no

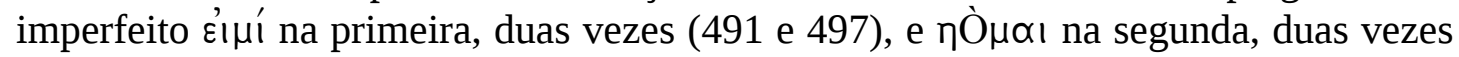
(509 e 523). Toda estrutura da narrativa segue assim opondo-se um a outro, como um padrão.

Em 541 inicia-se o terceiro ciclo, dividido em três partes com o verbo

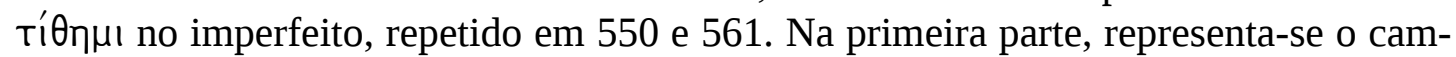
po lavrado sendo preparado para semeadura, com os bois puxando o arado e os rituais necessários para a boa colheita, o vinho no final da linha arada no campo. Na segunda parte, o campo real é ceifado, com a presença do rei, que se regozija, em silêncio, pois o ambiente é de trabalho coletivo de adultos e crianças. No final, o ritual é necessário: o festim para homens e deuses, preparado segundo conhecida prática sacrificial. Na terceira parte, a colheita em uma grande videira, com todos os detalhes: a vala e a cerca que a protegem, o caminho por onde passam os coletores e o ritual: o canto acompanhado da cítara com doce voz e dança bem ritmada.

Em 573 inicia-se o quarto ciclo, com o verbo пo $\varepsilon \omega$, no aoristo, repetido em 587, que retoma a duplicidade do segundo ciclo, em duas cenas: a primeira separada duas vezes em dois grupos, de homens e de cães, dois quadrados perfeitos, 4 e 9 respectivamente; dois leões atacam um touro do rebanho; os homens e os cães tentam defender o touro, sem sucesso; a segunda cena é a descrição de abrigos para homens e para o gado.

Em 590 inicia-se o quinto ciclo, com o verbo поı $i \hat{\lambda} \lambda \omega$, no imperfeito, retomando a unicidade do primeiro ciclo, como uma ampliação do centro, que contém a criação do cosmo, elemento fundamental, de que tudo parte em movimento circular e retilíneo, distanciando-se dele, para depois se reaproximar, coincidindo com ele. A dança, descrita até o verso 606, procura imitar o ato de criação através de formas reproduzidas em coro, circulares e retilíneos, que se pode interpretar como movimentos de um coro padrão, como haverá de existir na tragédia, a ser criada, mas pode-se entender também como reprodução artística do ato divino do criador, Hefesto, em sua forma humana, dança que inclui harmonia da música e dos movimentos.

Assim fica evidenciada uma sequência linear que em movimento circular parte e retorna ao mesmo ponto: 1232 1, referente aos ciclos do escudo de Aquiles. Essa sequência não é suposição mais ou menos forçada, ela existe no texto como que impressa, incontestável. Em consequência disso, sugestivos estudos especializados podem e devem ser feitos, relacionando um exame aprofundado desses versos da Ilíada e as teorias da criação, como no Timeu, de Platão, que não cabem aqui. 
Nos dois últimos versos, o criador punha a força do Rio-Oceano ao redor da orla extrema do escudo solidamente construído, reproduzindo o ato criador do universo, que na concepção grega é contido pelo Rio-Oceano.

\section{Ilíada (XVIII, 478-608)}

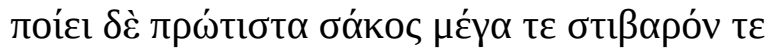
E fazia antes de tudo um escudo grande e maciço,

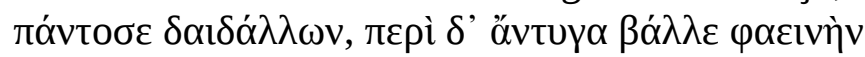
em tudo trabalhando com arte, em torno lançava uma orla brilhante,

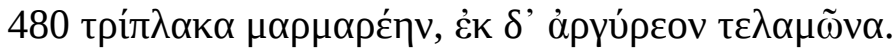
tríplice, cintilante, e um argênteo balteo.

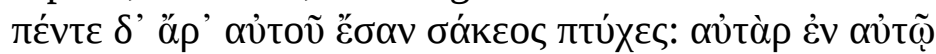
Cinco eram as regiões desse escudo: pois nele

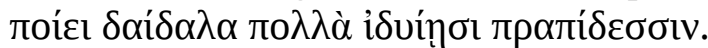
fazia muitos trabalhos artísticos com mente vidente.

Primeiro ciclo

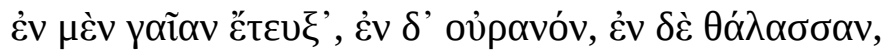
Inseriu terra, céu, mar,

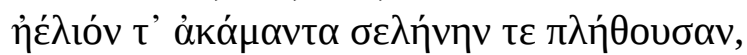
E sol incansável e lua que se completa,

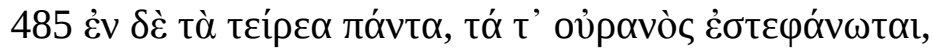
E todas as maravilhas de que está coroado o céu,

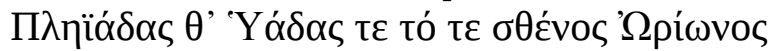
Plêiades, Híades e a força de Órion,

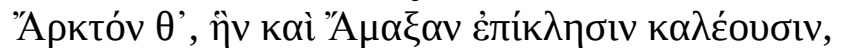
E a Ursa, que também chamam com epíteto de Carro,

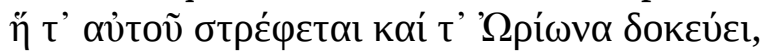
Que no mesmo lugar gira e observa o Órion,

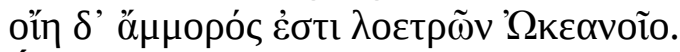
É a única sem participação dos banhos do Oceano.

Segundo ciclo I

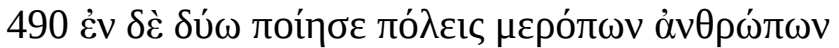
Reproduziu duas cidades de homens mortais

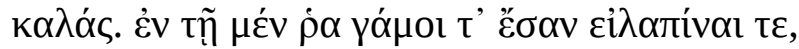
belas. Em uma havia casamentos e banquetes;

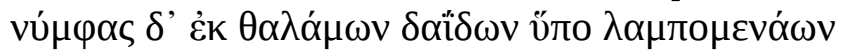
às noivas, desde os tálamos, sob tochas que brilham,

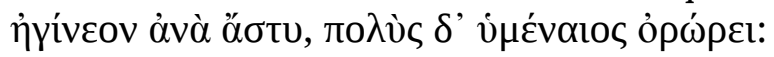
conduziam cidadela acima. Muito himeneu surgira:

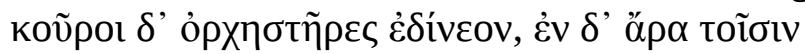
jovens dançarinos giravam, e entre eles

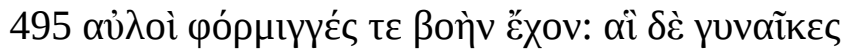
flautas e cítaras mantinham o coro, e as mulheres 


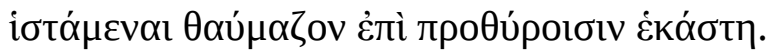
em pé admiravam, cada uma à sua porta.

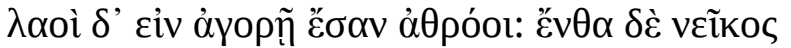

Pessoas na ágora estavam aglomeradas: ali disputa

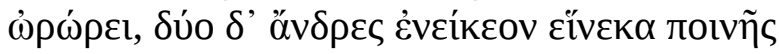

surgira, e dois homens disputavam por causa de uma pena,

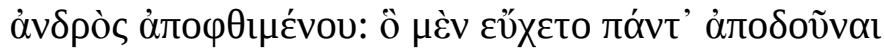

tendo sido morto um homem; um proclamava tudo ter pagado,

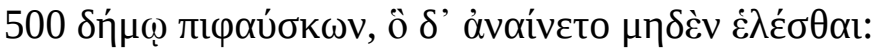

ao povo anunciando, outro negava, anunciando nada ter recebido.

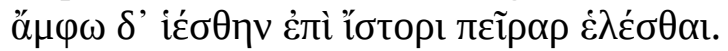

ambos buscavam, em presença de um árbitro, ter razão.

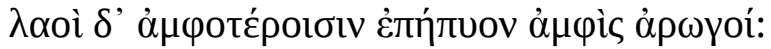

Homens a ambos apoiavam, de cada um dos dois defensores;

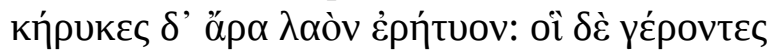

Então arautos continham o povo, e os velhos

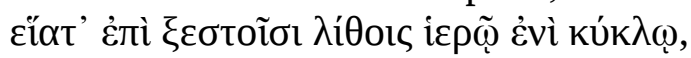

assentavam-se em polidas pedras em sagrado círculo,

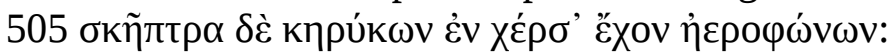

tendo nas mãos cetros de arautos de potente voz;

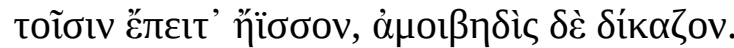

com que se alçavam e a sua vez julgavam.

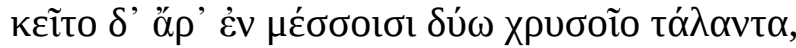

Jaziam no meio dois talentos de ouro,

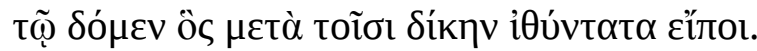

para dar ao que entre eles dissesse a sentença mais correta.

\section{Segundo ciclo II}

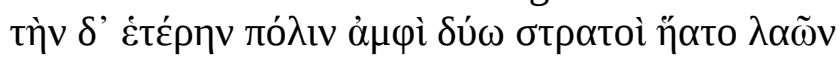

Em torno à outra cidade dois acampamentos de soldados estavam assentados,

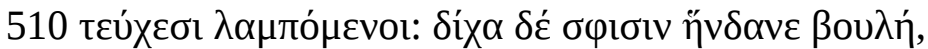

resplendentes com as armas; divergente, um conselho lhes agradava,

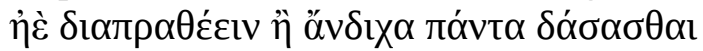

ou destruir ou em duas partes tudo ser dado,

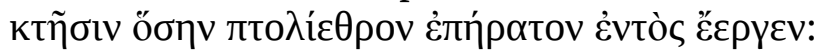

quanta posse a fortaleza desejável dentro contivesse.

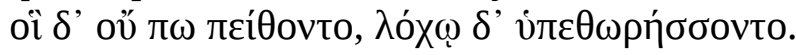

Mas aqueles jamais se persuadiam, e armavam uma cilada.

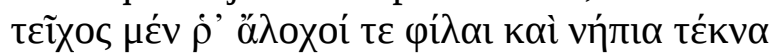

À muralha esposas queridas e filhos infantes

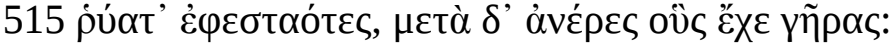

guardam, estando a postos, e ainda homens, que a velhice retinha;

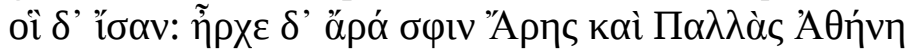

Eles saíam: antecedia-lhes então Ares e Palas Atena,

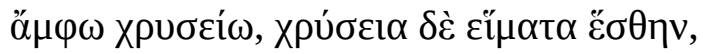

ambos de ouro, foram revestidos de vestes de ouro,

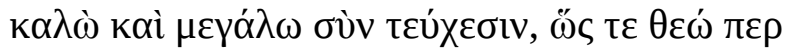

belos ambos e grandes com armas, como deuses propriamente 


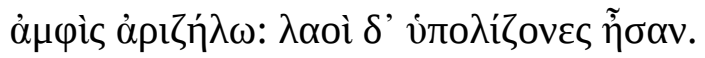

em torno bem visíveis; os homens eram menores.

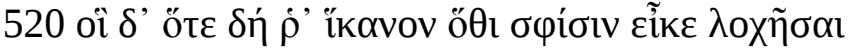

Eles, quando chegaram a um ponto em que lhes parecia bem armar a ci-

lada,

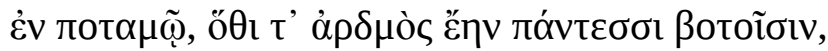

em um rio, em que havia um bebedouro para todos os rebanhos,

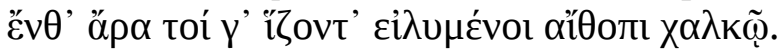

ali então ficaram, investidos de cintilante bronze.

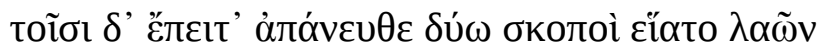

Depois, afastados deles, dois vigias da tropa estavam a postos,

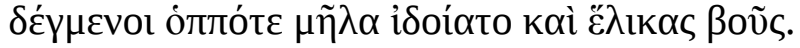

aguardando quando rebanhos aparecessem, e recurvos bois.

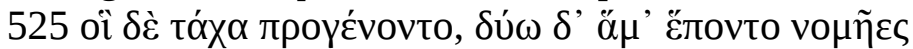

Eles logo surgiram, junto seguiam dois pastores

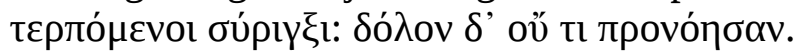
tocando flautas; dolo nenhum imaginam.

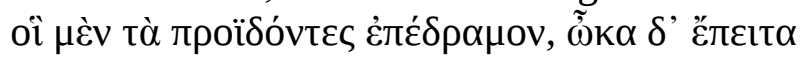

Aqueles, tendo-os visto, se apressaram, e logo depois

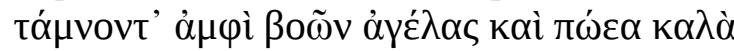

atalhavam de ambos os lados rebanhos de bois e belos rebanhos

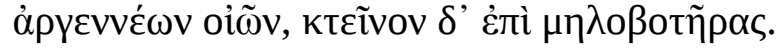

de argênteas ovelhas, e matavam depois os pastores.

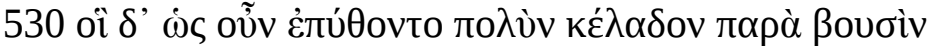

E eles, como ouviram muito barulho junto aos bois,

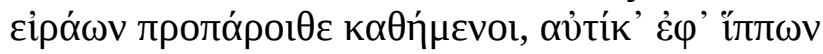
assentados em assembleia, logo sobre os cavalos de pés ligeiros

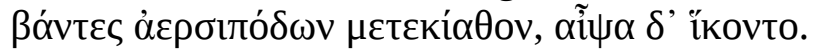
tendo subido, apressaram-se e súbito chegaram.

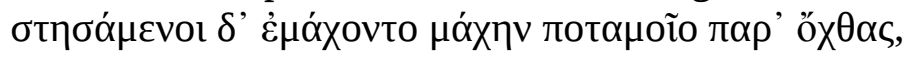
Estando ali, travavam batalha às margens do rio,

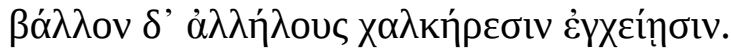

lançavam-se uns contra os outros com brônzeas lanças.

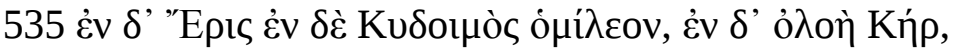

Estavam juntas Eris, kydoimos e Ker funesta,

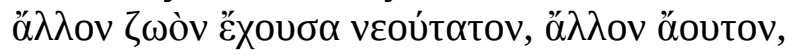
que um recém-ferido tinha vivo, outro não ferido,

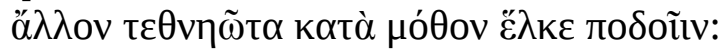

outro estando morto no tumulto arrastava pelos dois pés:

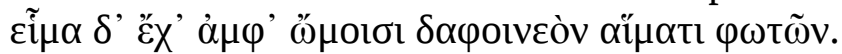

tinha a veste sobre ambos os ombros arroxeada de sangue de homens.

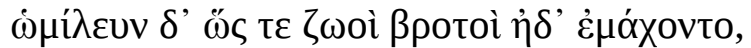

Juntavam-se como vivos mortais ou lutavam,

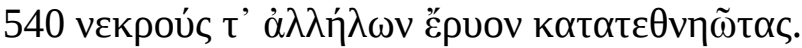

e arrastavam os cadáveres caídos uns dos outros.

Terceiro ciclo I

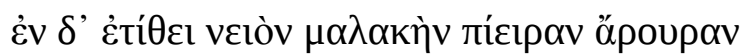

E punha um mole campo lavrado, rica aradura 


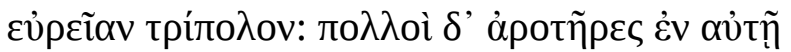
ampla, três vezes arada: muitos lavradores nela

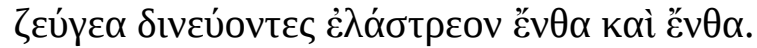
voltando a junta de bois estimulava-os aqui e ali.

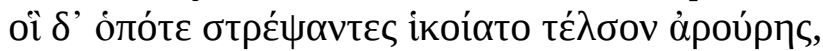
Quando eles, tendo girado, chegavam ao limite da aradura,

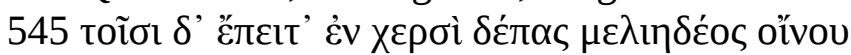
então dava-lhes em mãos uma copa de doce vinho

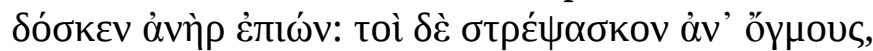
um homem que se aproximava; eles giram sobre os sulcos,

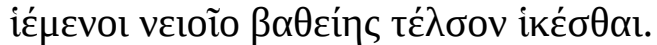
querendo chegar ao limite do largo campo lavrado,

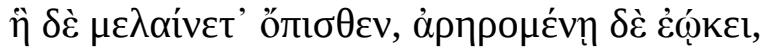
que se enegrecia atrás e assemelhava a solo arado,

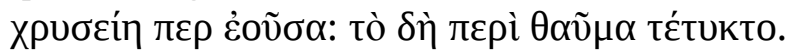
mesmo sendo de ouro. O prodígio era elaborado.

\section{Terceiro ciclo II}

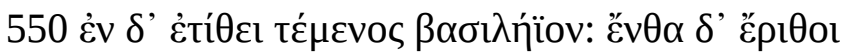
E pôs um campo real: ali ceifadores

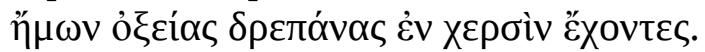
ceifavam, tendo afiadas foices em mãos.

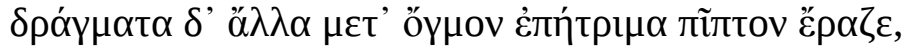
Uns punhados densos caíam em terra pelo sulco,

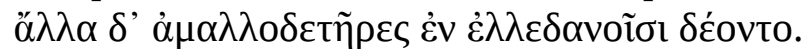
outros atadores atavam em feixes.

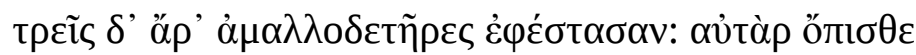
Três atadores estavam em pé, e logo atrás

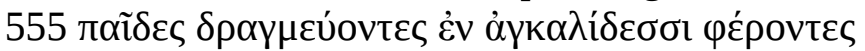
crianças apanhando-os, levando-os em braçadas

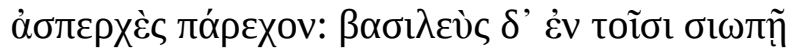
zelosamente levavam; um rei entre eles, em silêncio,

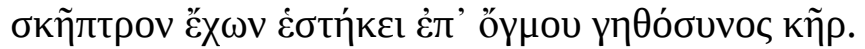
tendo um cetro estava em pé sobre o sulco, feliz no coração.

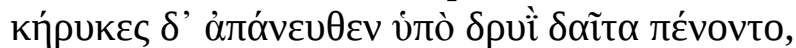
Arautos à distância sob um carvalho preparavam um banquete,

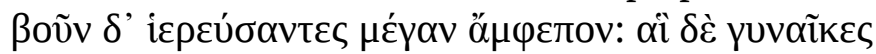
sacrificando um grande boi, o assavam; as mulheres

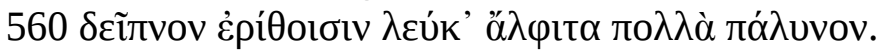

para refeição aos ceifadores aspergiam muita farinha branca de cevada.

Terceiro ciclo III

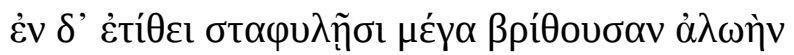

E punha uma vinha que se carregava grandemente de cachos maduros,

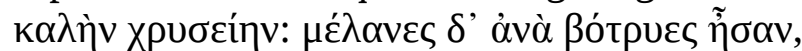
bela, de ouro: uvas escuras pendiam,

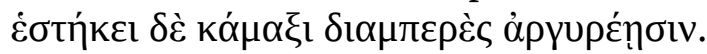
estava apoiada de parte a parte com estacas de prata. 


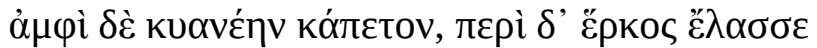

Em torno um escuro fosso, construiu em volta uma sebe

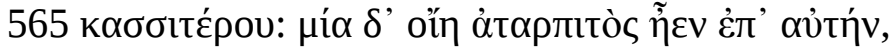
de estanho; somente um caminho havia para ela,

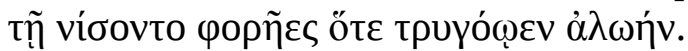

pelo qual passavam carregadores quando faziam a colheita na vinha.

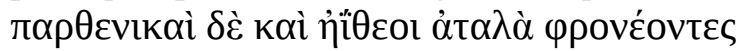

Meninas e meninos de ingênuos pensamentos

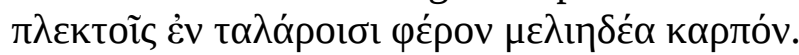

em canastras entrelaçadas levavam doce fruto.

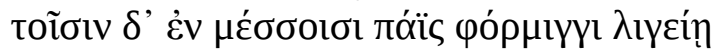

Em meio a eles uma criança com cítara canora

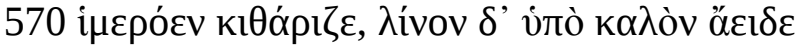

amavelmente tocava e um belo canto entoava

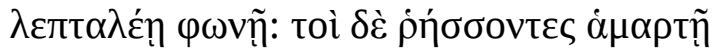

com tênue voz: e eles, batendo os pés com ritmo,

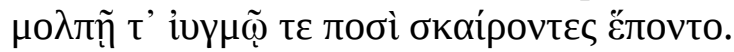

melodia e refrão, dançando, seguiam.

Quarto ciclo

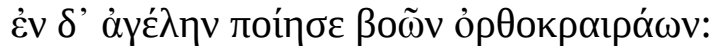

$\mathrm{E}$ fez um rebanho de bois de chifres erguidos:

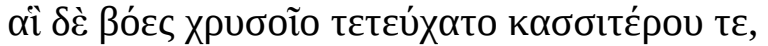

fizera as vacas de ouro e estanho,

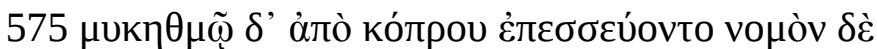

e com mugido apressavam-se do curral ao pasto,

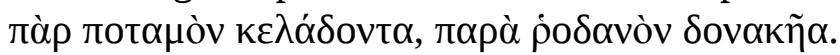

próximo a um rio rumorejante, junto a flexíveis canas.

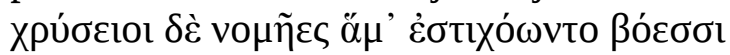

De ouro, quatro pastores enfileiravam junto com bois,

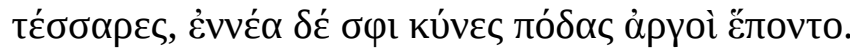

e nove cães de rápidos pés os seguiam.

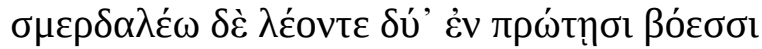

E dois formidáveis leões entre as primeiras reses

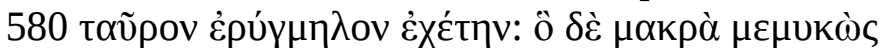

pegavam um touro berrante: ele, mugindo muito,

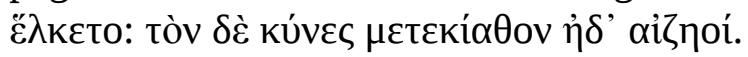

era arrastado; cães e jovens corriam a ele.

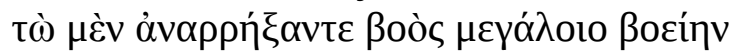

Eles, tendo rasgado a pele do grande boi,

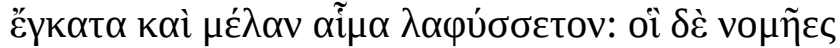

devoravam entranhas e negro sangue. Os pastores

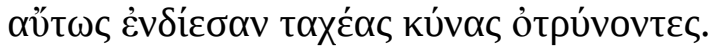

em vão incitavam os rápidos cães, estimulando-os.

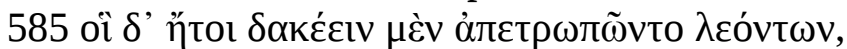

Estes se protegiam da mordida os leões,

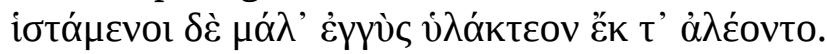

ficando muito perto, acuavam e desviavam. 


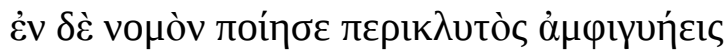
$\mathrm{E}$ fez o ínclito ambidestro um grande pasto

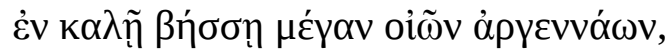
em um belo vale de ovelhas argênteas,

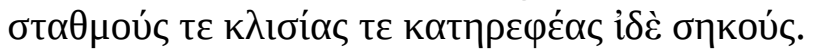
e estábulos e cabanas e cercados cobertos.

\section{Quinto ciclo}

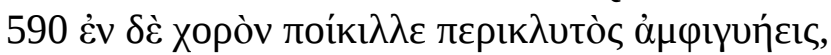
E elaborava um coro o ilustre ambidestro,

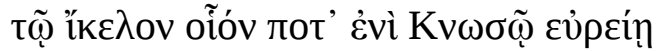
semelhante àquele tal como na ampla Cnosso

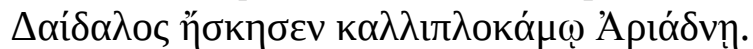
Dédalo praticou para Ariadne de bela trança.

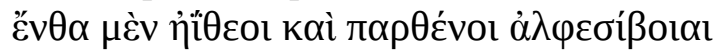
Ali meninos e meninas, cujos dotes valem muitos bois,

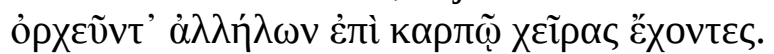
dançavam segurando as mãos de uns e de outras pelo punho.

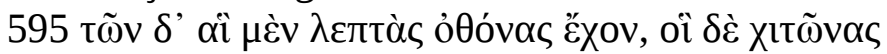
Dentre eles, elas tinham leves vestes de linho, eles vestiam

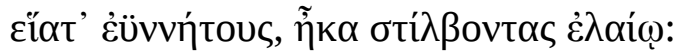
túnicas bem-tecidas suavemente esplendentes a azeite:

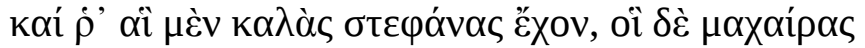
e elas tinham belas coroas, e eles espadins de ouro

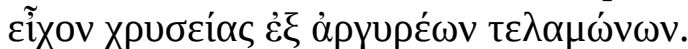
tinham desde argênteos bálteos.

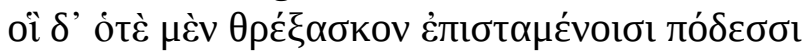
E eles então corriam com hábeis pés

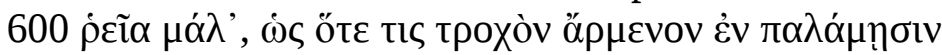
muito facilmente, como quando oleiro vai experimentar,

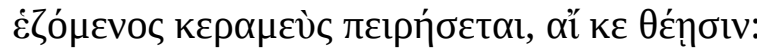
sentando-se, a roda ajustada nas palmas das mãos, se corre:

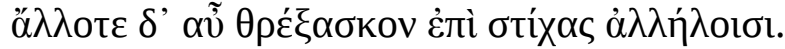
de outro modo ainda corriam em linhas, uns com os outros.

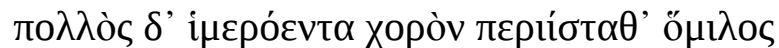
Muita gente estava ao redor do agradável coro тврло́ $\mu \varepsilon v o l:$ deleitando-se:

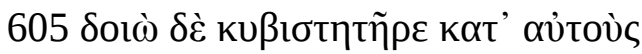
dois acrobatas em meio a eles

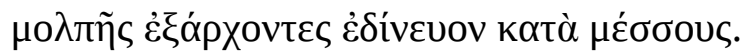
iniciando a dança giravam.

Orla extrema

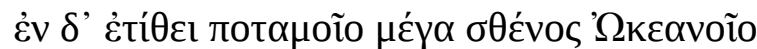
E punha a grande força do Rio-Oceano

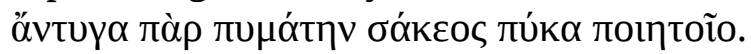
ao longo da orla extrema do escudo solidamente feito. 
Tradução:

\section{Juvino Alves Maia Júnior}

juvinojr@uol.com.br

Prof. Dr., Universidade Federal da Paraíba

Fonte: Homeri Opera in five volumes.

Oxford, Oxford University Press, 1920.

http://www.perseus.tufts.edu/hopper/text?doc $=$ Perseus\%3

Atext\%3A1999.01.0133\%3Abook\%3D18\%3Acard\%3D462

\section{Referências bibliográficas}

Homer. Homeri Opera in five volumes. Oxford, Oxford University Press, 1920. http://www.perseus.tufts.edu/hopper/text?doc=Perseus\%3Atext\%3A1999.01 .0133\%3Abook\%3D18\%3Acard\%3D462, acesso em 21/06/2014.

Musti, Domenico. Lo scudo di Achille, idee e forme di città nel mondo antico. RomaBari: Laterza, 2008.

Omero. Iliade, libro XVIII, lo scudo de Achille. Roma: Carocci, 2010. 